\title{
Metformin: A candidate for the treatment of gynecological tumors based on drug repositioning (Review)
}

\author{
HARUKO IRIE, KOUJI BANNO, MEGUMI YANOKURA, MIHO IIDA, \\ MASATAKA ADACHI, KANAKO NAKAMURA, KIYOKO UMENE, YUYA NOGAMI, \\ KENTA MASUDA, YUSUKE KOBAYASHI, EIICHIRO TOMINAGA and DAISUKE AOKI \\ Department of Obstetrics and Gynecology, School of Medicine, Keio University, Tokyo 160-8582, Japan
}

Received December 1, 2014; Accepted November 26, 2015

DOI: $10.3892 / 01.2016 .4075$

\begin{abstract}
Metformin is a first-line drug used for the treatment of type 2 diabetes. Recently, metformin has been reported to reduce the carcinogenic risk and inhibit tumor cell growth in glioma and breast cancer. The anticancer action of metformin involves the enhancement of phosphorylation of liver kinase B1, activation of adenosine monophosphate-activated protein kinase and inhibition of mammalian target of rapamycin, which reduces cell growth. Metformin is anticipated to exert antitumor effects in gynecological cancer, and its efficacy for the treatment of endometrial, breast and ovarian cancer has been suggested in preclinical studies and clinical trials. Although the effect of metformin on cervical cancer remains to be examined in clinical trials, its antitumor effects have been reported in preclinical studies. Thus, the use of metformin for the treatment of gynecological cancer may become a successful example of drug repositioning, following establishment of the drug's antitumor effects, risk evaluation, screening and validation of efficacy.
\end{abstract}

\section{Contents}

\section{Introduction}

2. Metformin in the treatment of type 2 diabetes

3. Effect of metformin on carcinogenic risk

4. The antitumor effect of metformin

5. Antitumor effect of metformin in endometrial cancer

6. Antitumor effect of metformin in breast cancer

7. Antitumor effect of metformin in ovarian cancer

8. Antitumor effect of metformin in cervical cancer

9. Clinical studies of metformin in gynecological cancer

10. Conclusion

Correspondence to: Dr Kouji Banno, Department of Obstetrics and Gynecology, School of Medicine, Keio University, 35 Shinanomachi, Shinjuku-ku, Tokyo 160-8582, Japan

E-mail:kbanno@z7.keio.jp

Key words: metformin, drug repositioning, endometrial cancer, ovarian cancer, breast cancer

\section{Introduction}

Metformin is an oral biguanide that is used worldwide for the treatment of type 2 diabetes (1). Previous studies have provided evidence that long-term administration of metformin may reduce the carcinogenic risk in various organs, and may have an inhibitory effect on cell growth in breast and colon cancer, as well as glioma $(2,3)$. The mechanism underlying the antitumor effect of metformin is considered to involve the activation of adenosine monophosphate-activated protein kinase (AMPK) and inhibition of mammalian target of rapamycin (mTOR), which reduces cell growth (4). Focusing on gynecological cancer, as carcinogenesis in endometrial cancer appears to be associated with obesity, type 2 diabetes and hyperestrogenic conditions, metformin may be effective for prevention and improvement of prognosis in endometrial cancer (5). Thus, the effect of metformin on gynecological tumors, particularly endometrial cancer, is currently under investigation.

The aim of drug repositioning is to identify novel pharmacological effects for conventional drugs, in which human safety and pharmacokinetics are already established, and to expand the application of the drug for the treatment of additional diseases (6). As the adverse reactions of the repositioned drugs are known from previous clinical trials, safety is guaranteed, and the time and cost of drug discovery are considerably alleviated (6). Despite recent efforts, the efficacy of the existing antitumor drugs requires improvement, since they frequently cause adverse reactions, including nausea, vomiting, hair loss, nephrotoxicity and myelosuppression, which may limit their use. We hypothesize that by combining traditional antitumor drugs with novel antitumor agents identified by drug repositioning, improved therapeutic efficacy and reduced adverse reactions may be achieved. In the present review, the clinical application of metformin for the treatment of different types of gynecological cancer is evaluated from the perspective of drug repositioning.

\section{Metformin in the treatment of type 2 diabetes}

Metformin is an oral biguanide that is safe and cost-effective for the treatment of type 2 diabetes (1). Structurally, metformin contains two conjugated guanidine groups and an additional 


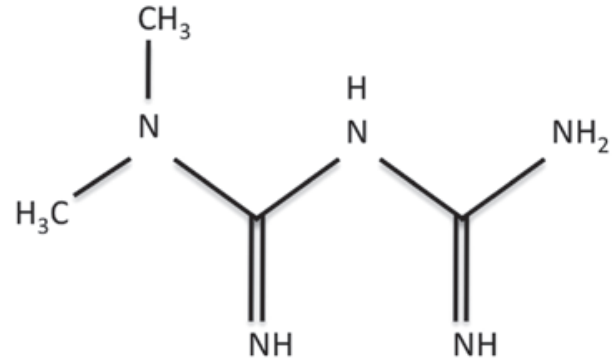

Figure 1. Structure of metformin. Metformin contains two conjugated guanidine groups and an additional amine.

amine (7) (Fig. 1). Metformin is one of the first-line agents prescribed worldwide for the treatment of type 2 diabetes $(1,8)$, based on its inhibition of insulin-dependent hepatic gluconeogenesis, promotion of glucose uptake into surrounding cells by improvement of insulin resistance and reduction of free fatty acids by inhibition of lipolysis (9-11). Metformin additionally inhibits the development of macroangiopathy to a greater extent than sulfonylureas do, which may be utilized for the treatment of type 2 diabetes (12).

Metformin enhances glucose consumption in the intestine and produces lactic acid, which is used in hepatic gluconeogenesis (13). This causes adverse reactions, including lactic acidosis, intestinal symptoms such as diarrhea and abdominal pain, and vitamin B12 deficiency (14). Lactic acidosis increases the risk of impaired hemodynamics due to ischemia and shock, nephropathy, hepatic dysfunction, alcoholism and heart failure (15-18). Therefore, it is clinically important to consider the balance between the therapeutic effects and the risks of adverse reactions when using metformin (17). Nevertheless, the incidence of lactic acidosis with metformin is $9 / 100,000$ patients/year, whereas with phenformin, an alternative drug used for the treatment of type 2 diabetes, 40-64/100,000 patients/year experience lactic acidosis (19). Therefore, metformin is generally considered to be safe, compared with alternative antidiabetic drugs (19).

\section{Effect of metformin on carcinogenic risk}

Type 2 diabetes and insulin resistance increase the carcinogenic risk in the large intestine, lung, breast, prostate gland and pancreas (20-25). A number of studies have evaluated the effects of metformin on cancer prevention. In a population-based study including 11,876 patients with type 2 diabetes, Evans et al (26) reported a reduced incidence of cancer in patients treated with metformin, compared with patients not treated with metformin [odds ratio (OR), 0.79; 95\% confidence interval (CI), 0.67-0.93]. Bowker et al (27) compared patients with type 2 diabetes in the metformin (monotherapy or combined) group and sulfonylurea monotherapy group, and reported that the cancer mortality rate was significantly decreased in the metformin group [hazard ratio (HR), 0.80; 95\% CI, 0.65-0.98; $\mathrm{P}=0.03$ ), compared with the sulfonylurea group. In a study of 4,085 patients exhibiting type 2 diabetes, Libby et al (28) identified that the incidence of cancer in patients treated with metformin (7.3\%) was significantly lower than that observed in patients treated with alternative drugs (11.6\%). Following adjustment for confounding factors, the authors observed that the use of metformin significantly reduced the risk of cancer (HR, 0.63; 95\% CI, 0.53-0.75). The results of the aforementioned studies suggest that metformin is able to reduce the carcinogenic risk in patients with type 2 diabetes.

\section{The antitumor effect of metformin}

Multiple pathways are considered to be involved in the antitumor activity of metformin (4,29-32) (Fig. 2). The primary action of metformin occurs via activation of AMPK (33). Metabolically, AMPK inhibits the expression of certain enzymes involved in hepatic gluconeogenesis, enhances glucose uptake into muscle and fat cells, and increases insulin sensitivity in cells, resulting in decreased insulin levels $(33,34)$. Furthermore, the fact that the metformin-induced activation of AMPK is mediated by the tumor suppressor liver kinase B1 (LKB1) suggests the antitumor potential of metformin (29). AMPK inhibits the activity of mTOR in the phosphoinositide 3-kinase/Akt/mTOR signal transduction pathway, which stimulates cellular proliferation $(30,31)$. AMPK is also known to inhibit cell cycle progression via the activation of tumor protein p53 (4).

Additional mechanisms of metformin that do not involve AMPK have been reported. Metformin inhibits cell cycle progression by decreasing cyclin D1 expression (35), and Cantrell et al (32) identified that telomerase activity was inhibited by metformin. However, the mechanism of action of metformin remains to be fully elucidated, for which further studies are required.

\section{Antitumor effect of metformin in endometrial cancer}

Metformin may be an effective adjuvant for the treatment of endometrial cancer, based on the observation that type 2 diabetes and obesity are risk factors of endometrial cancer (5). Epidemiological data has demonstrated that obese individuals possess a significantly increased risk of developing endometrial cancer in comparison with non-obese individuals (risk ratio, 6.25; 95\% CI, 3.75-10.42; $\mathrm{P}<0.001$ ) (36). An additional risk factor for endometrial cancer is polycystic ovarian syndrome (PCOS), in which hyperinsulinemia and hyperandrogenism are the two central pathological conditions (37). Metformin has a therapeutic effect on the anovulatory cycle in PCOS (38), and is expected to reduce the carcinogenic risk in endometrial cancer (39).

Metformin is additionally likely to have a significant role in the prevention of endometrial cancer via cell cycle arrest and induction of apoptosis (32). In preclinical studies, Cantrell et al (32) observed that metformin caused G1 arrest at a low dose of $1 \mathrm{mM}$, and apoptosis via activation of caspase-3 at a high dose of 2-5 $\mathrm{mM}$ in vitro.

Telomere maintenance by telomerase has a significant role in tumor growth, and the messenger (m)RNA levels of human telomerase reverse transcriptase (hTERT) are used as an index for telomerase activity and cell growth (32). Metformin suppresses the mRNA expression of hTERT in endometrial cancer cells in a dose-dependent manner, leading to the inhibition of telomerase activity (35). The suppression of hTERT mRNA may be a direct effect of metformin or 


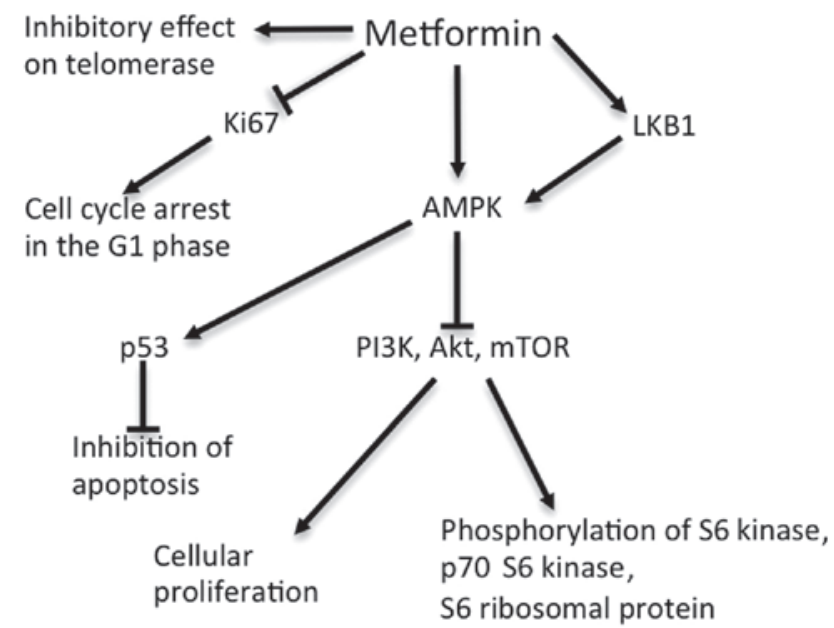

Figure 2. Antitumor mechanism of metformin. The primary pathway is considered to be the AMPK/PI3K/Akt/mTOR signal transduction pathway. Recent studies $(4,29-32,35)$ have revealed that multiple signaling pathways contribute to the antitumor mechanism of metformin. AMPK, adenosine monophosphate-activated protein kinase; PI3K, phosphoinositide 3-kinase; mTOR, mammalian target of rapamycin; LKB1, liver kinase B1.

a secondary effect due to cell cycle arrest, as endometrial, ovarian and cervical cancer cell growth is additionally inhibited by rapamycin and accompanied by a decrease in hTERT mRNA (35). A direct inhibition caused by metformin has been suggested, due to the observation that rapamycin suppressed hTERT mRNA without cell growth inhibition or cell cycle arrest in cell lines that were resistant to rapamycin, indicating that a reduction in hTERT mRNA is able to occur independently from cell cycle arrest (40).

Progesterone is utilized for the treatment of early endometrial cancer. However, the therapeutic effect of progesterone in endometrial cancer cells is insufficient, due to the downregulation of progesterone receptor (PR) in these cells (41). Xie et al (41) identified that metformin and progesterone had a synergistic effect in the treatment of endometrial cancer. Metformin inhibits the phosphorylation of S6 ribosomal protein (S6RP), increases PR expression and inhibits mTOR via AMPK phosphorylation, which enhances the efficacy of medroxyprogesterone acetate (MPA) in the treatment of endometrial cancer (42).

Ko et al (43) investigated the efficacy of metformin in 1,495 patients exhibiting endometrial cancer, including $363(24 \%)$ patients with diabetes. Patients treated with metformin (54\% of diabetic patients in the study) demonstrated significantly improved recurrence-free survival (RFS) and overall survival (OS) rates in comparison with patients who were not administered metformin. RFS in the non-metformin group was reduced by 1.8 -fold $(95 \% \mathrm{CI}$, 1.1-2.9; $\mathrm{P}=0.02)$, while $\mathrm{OS}$ was reduced by 2.3 -fold $(95 \% \mathrm{CI}$, 1.3-4.2; $\mathrm{P}=0.005)$. However, there was no association between metformin treatment and time to recurrence, indicating that metformin has a survival benefit for mortality, but does not prolong the time to recurrence, for reasons that remain to be elucidated (43). Thus, additional studies are required to confirm if adjuvant therapy with metformin is effective for patients exhibiting endometrial cancer, regardless of the complication of diabetes.

\section{Antitumor effect of metformin in breast cancer}

Breast cancer is associated with type 2 diabetes (36), and a previous epidemiological study demonstrated that type 2 diabetes increased the risk of developing breast cancer by $10-20 \%$ (44).

Triple-negative (TN) breast cancer refers to breast cancer cases that do not express the genes for estrogen receptor (ER), PR and human epidermal growth factor receptor 2 (HER-2) (45). TN breast cancer develops in perimenopausal women possessing a high body mass index (BMI) and overexpression of epidermal growth factor receptor, and has been identified to be highly sensitive to metformin (45). A previous study revealed that metformin was able to inhibit cell growth of $\mathrm{TN}$ breast cancer at a similar dose to that utilized for the treatment of type 2 diabetes by suppressing Ki67, arresting the cell cycle in G1 phase, and inducing intrinsic and extrinsic apoptosis via caspase-8 and -9 (45). The efficacy of metformin for the treatment of common subtypes of breast cancer, including luminal $\mathrm{A}$ and $\mathrm{B}$ and HER-2 ${ }^{+}$, has additionally been demonstrated. Colonization and tumor growth were simultaneously inhibited by metformin, and these effects occurred through a non-apoptotic mechanism, in which cyclin D1 and E2F transcription factor 1 (E2F1), which promote the transition from G1 to $\mathrm{S}$ phase, were implicated (46). In addition, metformin was able to alter tyrosine kinase signaling, downregulates HER-2 and activates mitogen-activated protein kinase at an identical dose to that utilized for the treatment of type 2 diabetes (46).

Overexpression of the insulin and insulin-like growth factor (IGF)-1 receptors is involved in the carcinogenesis of breast cancer, and breast cancer cell lines such as MCF-7 are responsive to insulin and IGF-1 (47). The absence of an inhibitory effect of metformin on cell growth following small interfering RNA inhibition of AMPK suggested that the effect of metformin on breast cancer cells occurs via AMPK (48).

The efficacy of metformin has been demonstrated in diabetic women exhibiting breast cancer in a retrospective study (49). Of the 155 diabetic patients included in the study, 68 received metformin and 87 did not, along with anthracycline-based chemotherapy regimens (49). The pathological complete response rate was $24 \%$ in the metformin-treated group, compared with $8 \%$ in the non-metformin-treated group $(\mathrm{P}=0.07)(49)$. Additional phase II and phase III studies are ongoing. The METEOR study is a phase II randomized trial of metformin plus letrozole vs. placebo plus letrozole, which aimed to assess the antitumor effects of metformin in postmenopausal non-diabetic patients exhibiting $\mathrm{ER}^{+}$breast cancer (50). An ongoing phase III clinical trial termed NCIC CTG MA.32, which aimed to study the effects of metformin on non-diabetic patients with breast cancer, requires a follow-up period of several years in order to evaluate the effects of metformin on mortality and define an optimal dose of metformin for the treatment of early breast cancer (51).

The optimal dose of metformin for the treatment of breast cancer remains to be elucidated. However, 1,500-2,250 mg/day metformin was observed to be required in order to reduce tumor size in xenograft models $(50,52)$, 
and in the NCIC CTG MA.32 trial, the metformin group was designed to receive $1,700 \mathrm{mg} /$ day of this drug (51). These doses are tolerated in the treatment of type 2 diabetes (8).

\section{Antitumor effect of metformin in ovarian cancer}

The potential pharmacological effects of metformin in ovarian cancer are of interest. Obesity potentially contributes to the onset of ovarian cancer, and may additionally be stimulated by androgens, as in PCOS $(36,39)$. Hyperandrogenism is caused by hyperinsulinemia, inhibition of IGF binding protein 1 (IGFBP1) and increased IGF-1 activity (39). Based on the risk reduction for ovarian cancer exhibited by oral contraceptives with anti-androgen activity (53) and the effects of metformin on PCOS, obesity and other tumors, we hypothesize that metformin may demonstrate efficacy for the treatment of ovarian cancer. Metformin inhibits tumor growth and induces apoptosis in ovarian cancer cells in vitro, as reported by Gotlieb et al (54), who identified that metformin inhibited cell growth in OVCAR-3 and OVCAR-4 cells in a dose-dependent manner, and administration of metformin in combination with cisplatin enhanced this pharmacological effect. These effects were induced by decreased phosphorylation of p70 S6 kinase (p70S6K) and S6K via AMPK phosphorylation (54).

A number of epidemiological studies have investigated the effects of metformin in ovarian cancer. In a case-control study of 1,611 diabetic patients, Bodmer et al (55) identified that the carcinogenic risk in the metformin-treated group was significantly lower (OR, $0.61 ; 95 \% \mathrm{CI}, 0.30-1.25)$ than in the sulfonylurea-treated (OR, 1.26; 95\% CI, 0.65-2.44) and insulin-treated groups (OR, 2.29; 95\% CI, 1.13-4.65). In a study including 1,454 diabetic patients treated with metformin and 2,897 diabetic patients who were not administered metformin for a median duration of 4.0 years, Home et al (56) observed that none of the patients in the metformin group developed ovarian cancer, whereas 3 patients in the non-metformin group did. In an analysis with a median duration of 5.5 years, $6 / 3,344$ patients treated with metformin and 3/1,103 patients who were not treated with metformin developed ovarian cancer (56).

In a systematic review of 28 studies, Zhang and Li (57) identified that metformin decreased mortality associated with ovarian cancer (relative risk (RR), $0.44 ; 95 \%$ CI, 0.30-0.64; $\mathrm{P}<0.001)$. In an epithelial ovarian cancer study, the effect of metformin on survival rate was examined in 61 metformin-treated diabetic patients and 178 non-diabetic controls (58). The 5-year disease-specific survival (DSS) rate in the metformin group was significantly increased, compared with the control group (67 vs. $47 \%$; $\mathrm{P}=0.007$ ) (58). Following adjustment for background factors including BMI, tumor grade, histology and chemotherapy, metformin remained an independent predictor of survival (58). In the same study, the 5 -year DSS rate was compared between the metformin-treated diabetic group and the diabetic control group (patients on diabetic treatment other than metformin). The 5-year DSS rate was significantly reduced in the insulin (43\%) and alternative antidiabetic medication group (34\%; $\mathrm{P}=0.004)$, compared with the metformin-treated group. There were a limited number of patients exhibiting diabetes and ovarian cancer, and the small number of cases $(n=61)$ is a limitation of that study (58).
However, the results clearly demonstrated the overall efficacy of metformin for the treatment of ovarian cancer (58). As diabetes itself is known to be a poor prognostic factor for ovarian cancer, and diabetic patients are also likely to exhibit other poor prognostic factors, including cardiovascular disease and surgical history, the therapeutic effects of metformin may be overestimated when compared with non-metformin treated diabetic patients (58). Thus, it is a matter of discussion whether the antitumor effects of metformin should be compared with diabetic or non-diabetic controls in future studies.

\section{Antitumor effect of metformin in cervical cancer}

There have been few studies discussing the efficacy of metformin for the treatment of cervical cancer. However, based on its effects on tumor inhibition, metformin is likely to inhibit cervical cancer cell growth $(59,60)$. Xiao et al (61) investigated the kinetics of metformin in cervical cancer cells and evaluated LKB1 activity in these cells. The authors observed that metformin inhibited the growth of the C33A, ME180 and CaSki cervical cancer cell lines, but exhibited reduced efficacy against HeLa, HT-3 and MS751 cells (61). Following analysis of LKB1/AMPK/mTOR signaling, metformin-sensitive cervical cancer cells were identified to activate AMPK via LKB1 and inhibit mTOR (61). In contrast, sensitivity to metformin was lost in LKB1-knockdown cells, whereas in cervical cancer cells expressing LKB1, metformin induced apoptosis and autophagy (61). These results suggest that metformin may be a promising drug for the treatment of cervical cancer, particularly in tumor cells expressing LKB1, by increasing LKB1 activity and activating AMPK (61).

\section{Clinical studies of metformin in gynecological cancer}

In antitumor mechanisms in vitro (Fig. 3), metformin arrests the cell cycle in endometrial cancer cells, decreases hTERT mRNA and inhibits phosphorylation of S6RP, resulting in inhibition of signaling downstream of the mTOR pathway $(35,42)$. Metformin additionally antagonizes IGF-2, enhances expression of PR and improves the antitumor effect of MPA in cancer cells (41). The antitumor effect of metformin in breast, cervical and ovarian cancer also involves the inhibition of mTOR via AMPK activity $(48,54,61)$.

Based on these findings, the efficacy of metformin for the treatment of gynecological cancer has been examined in clinical studies, and the results have been analyzed using RR in systematic reviews (57). Two studies have demonstrated the efficacy of metformin for the treatment of endometrial cancer $(43,62)$. In these studies, the RR of treatment with metformin was 0.49 (95\% CI, 0.32-0.73; P=0.001), with no difference in the results in meta-analysis and no heterogeneity $\left(\mathrm{I}^{2}=0 \%\right)(58)$. A total of four studies have demonstrated that metformin improves overall mortality in breast cancer (63-66), contrarily to three other studies (67-69), which did not observe any efficacy for this drug. The RR of treatment with metformin in the aforementioned studies was 0.70 (95\% CI, $0.55-0.88 ; \mathrm{P}=0.003)(58)$. High heterogeneity was identified in these studies $\left(I^{2}=75 \%\right)$, but no publication bias. He et al (63) demonstrated that administration of metformin markedly decreased mortality specific to breast cancer (63), although 
Table I. Effects of metformin in gynecological cancer prevention.

\begin{tabular}{lccrr}
\hline Type of cancer & Relative risk for all-cause mortality & 95\% Confidence interval & P-value & Heterogeneity, $\mathrm{I}^{2}, \%$ \\
\hline Endometrial & 0.49 & $0.32-0.73$ & 0.001 & 0 \\
Breast & 0.70 & $0.55-0.88$ & 0.003 & 75 \\
Ovarian & 0.44 & $0.30-0.64$ & $<0.001$ & 0 \\
\hline
\end{tabular}

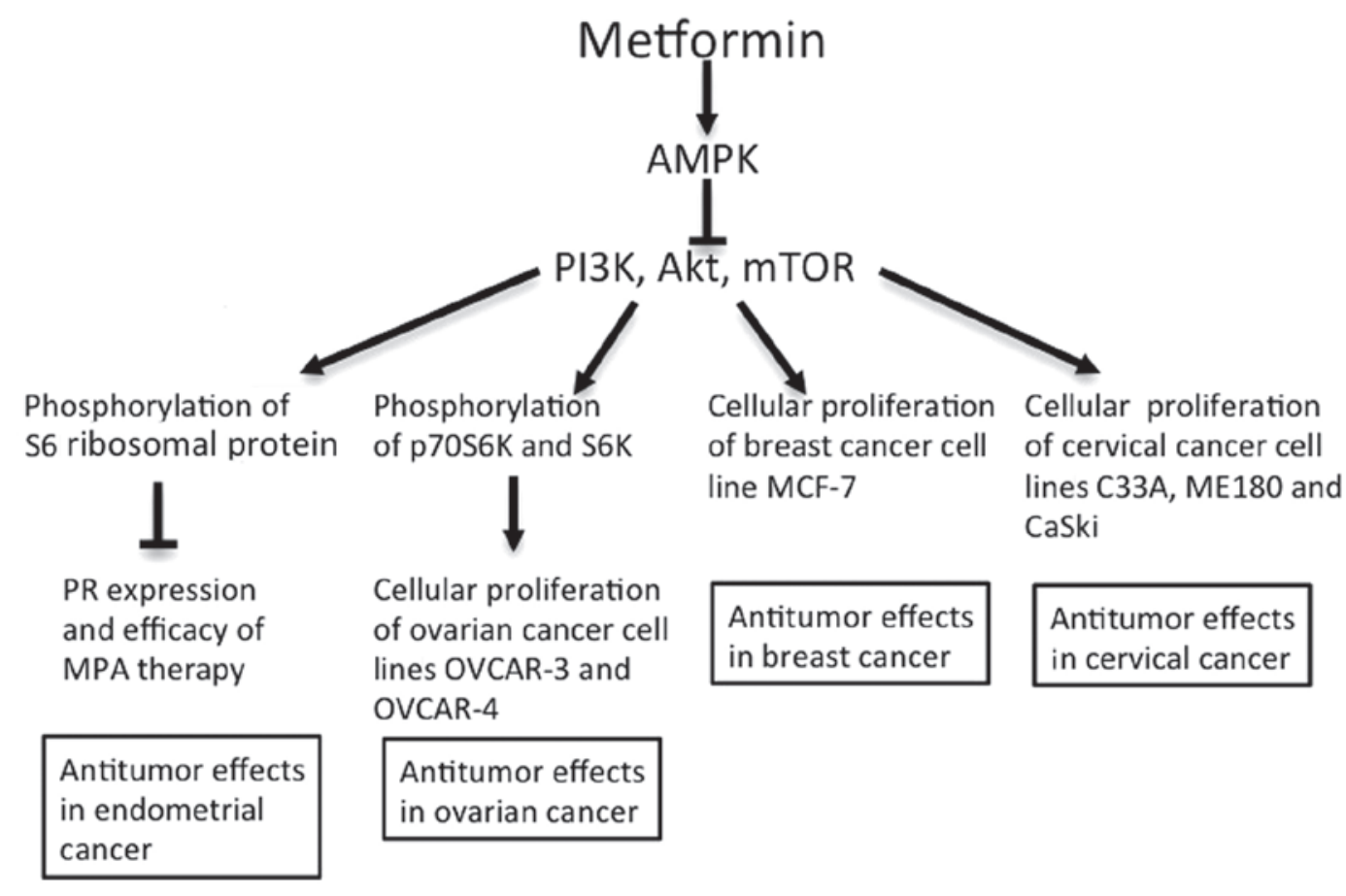

Figure 3. Antitumor effects of metformin in gynecological cancer. Antitumor effects of metformin have been demonstrated in endometrial, ovarian, breast and cervical cancer in vitro $(41,46-48,54,61)$. AMPK, adenosine monophosphate-activated protein kinase; PI3K, phosphoinositide 3-kinase; mTOR, mammalian target of rapamycin; PR, progesterone receptor; MPA, medroxyprogesterone acetate; S6K, S6 kinase.

their findings did not correlate with the results of two other studies $(67,68)$. The RR in these studies was $0.83(95 \% \mathrm{CI}$, 0.63-1.08; $\mathrm{P}=0.16)$, and moderate heterogeneity was apparent $\left(\mathrm{I}^{2}=47 \%\right)(57)$. The high $\mathrm{I}^{2}$ values in the analyses of trials of metformin for breast cancer reflected the varying results among the studies. In ovarian cancer, an association between the use of metformin and overall mortality has been identified in three studies $(58,69,70)$. The RR in these studies was 0.44 (95\% CI, 0.30-0.64; $\mathrm{P}<0.001$ ), and there was no heterogeneity $\left(\mathrm{I}^{2}=0 \%\right)(57)$. A previous study demonstrated that metformin improved progression-free survival, with a relapse HR of 0.38 (95\% CI, 0.16-0.90; $\mathrm{P}=0.03$ ) (57). Overall, the results of the above studies indicate that metformin significantly increases survival in endometrial, breast and ovarian cancer (Table I). The efficacy of metformin in the treatment of cervical cancer has not been examined clinically to date.

Concurrent antitumor therapies used alongside metformin, dose adjustment, cancer stage, tumor size and histology are significant prognostic factors. However, they are not described in the majority of studies (57). We hypothesize that failure to adjust for these confounding factors may cause high heterogeneity. Ethnicity, education level and access to medical care may additionally influence survival, and these factors may bias estimates of the efficacy of metformin (57). Future studies should include clinical trials that consider these factors in order to increase the cohort size, reduce bias and evaluate the effect of metformin more accurately. It is additionally important to identify the optimum dose of metformin based on adverse reactions (57).

\section{Conclusion}

Metformin is a first-line drug that is used for the treatment of type 2 diabetes, and has additionally been identified to decrease carcinogenic risk and inhibit cancer cell growth $(2,3)$. The antitumor mechanism of metformin involves the inhibition of the mTOR pathway through AMPK activation, as demonstrated in a number of studies on gynecological cancer $(42,48,54,61)$. However, additional details of the mechanism responsible for the antitumor effects of metformin remain to be elucidated. In endometrial cancer, cell cycle arrest by metformin has been observed in vitro, and inhibition of telomerase activity may be an important mechanism to explain the antitumor activity of this drug (35). Metformin additionally has an increased antitumor effect when administered in combination with MPA therapy (41). Clinical studies of metformin have demonstrated 
efficacy and safety in breast, endometrial and ovarian cancer $(43,49,50,55-58)$. The effect in cervical cancer has not been examined in clinical studies thus far, although efficacy of metformin in vitro has been observed (61).

In conclusion, drug repositioning allows rapid clinical application of a drug with high safety and low cost (6). For drug repositioning of metformin, it will be particularly important to understand its antitumor mechanism, evaluate its adverse reactions and risks in clinical application, and determine the optimum dose required for the treatment of gynecological cancer.

\section{Acknowledgements}

The authors would like to thank Dr K. Nakagawara (Keio University School of Medicine, Tokyo, Japan) and Dr K. Aoyama (Keio University School of Medicine, Tokyo, Japan) for their helpful assistance. The present study was supported by grants from the Medical Research Encouragement Prize of The Japan Medical Association (Tokyo, Japan) and the Keio Gijuku Academic Development Funds of Keio University (Tokyo, Japan).

\section{References}

1. Nathan DM, Buse JB, Davidson MB, Heine RJ, Holman RR, Sherwin R and Zinman B; Professional Practice Committee, American Diabetes Association; European Association for the Study of Diabetes: Management of hyperglycaemia in type 2 diabetes: A consensus algorithm for the initiation and adjustment of therapy. A consensus statement from the American Diabetes Association and the European Association for the Study of Diabetes. Diabetologia 49: 1711-1721, 2006.

2. Aljada A and Mousa SA: Metformin and neoplasia: Implications and indications. Pharmacol Ther 133: 108-115, 2012.

3. Soritau O, Tomuleasa C, Aldea M, Petrushev B, Susman S, Gheban $\mathrm{D}$, Ioani H, Cosis A, Brie I, Irimie A, et al: Metformin plus temozolomide-based chemotherapy as adjuvant treatment for WHO grade III and IV malignant gliomas. J BUON 16: 282-289, 2011.

4. Emami Riedmaier A, Fisel P, Nies AT, Schaeffeler E and Schwab M: Metformin and cancer: From the old medicine cabinet to pharmacological pitfalls and prospects. Trends Pharmacol Sci 34: 126-135, 2013.

5. Campagnoli C, Abbà C, Ambroggio S, Brucato T and Pasanisi P: Life-style and metformin for the prevention of endometrial pathology in postmenopausal women. Gynecol Endocrinol 29: $119-124,2013$.

6. Ashburn TT and Thor KB: Drug repositioning: Identifying and developing new uses for existing drugs. Nat Rev Drug Discov 3: 673-683, 2004.

7. Moiseeva O, Deschênes-Simard X, Pollak M and Ferbeyre G: Metformin, aging and cancer. Aging (Albany NY) 5: 330-331, 2013.

8. Nathan DM, Buse JB, Davidson MB, Ferrannini E, Holman RR, Sherwin R and Zinman B; American Diabetes Association; European Association for Study of Diabetes: Medical management of hyperglycemia in type 2 diabetes: A consensus algorithm for the initiation and adjustment of therapy: A consensus statement of the American Diabetes Association and the European Association for the Study of Diabetes. Diabetes Care 32: 193-203, 2009.

9. Bailey CJ: Biguanides and NIDDM. Diabetes Care 15: 755-772, 1992.

10. Bailey CJ and Turner RC: Metformin. N Engl J Med 334: 574-579, 1996.

11. Stumvoll M, Nurjhan N, Perriello G, Dailey G and Gerich JE: Metabolic effects of metformin in non-insulin-dependent diabetes mellitus. N Engl J Med 333: 550-554, 1995.

12. Morgan CL, Mukherjee J, Jenkins-Jones S, Holden SE and Currie CJ: Association between first-line monotherapy with sulphonylurea versus metformin and risk of all-cause mortality and cardiovascular events: A retrospective, observational study. Diabetes Obes Metab 16: 957-962, 2014.
13. Chan NN, Brain HP and Feher MD: Metformin-associated lactic acidosis: A rare or very rare clinical entity? Diabet Med 16: 273-281, 1999.

14. Kilo C: Metformin: A safe and effective treatment in the management of NIDDM. Mo Med 94: 114-123, 1997.

15. Vasisht KP, Chen SC, Peng Y and Bakris GL: Limitations of metformin use in patients with kidney disease: Are they warranted?. Diabetes Obes Metab 12: 1079-1083, 2010.

16. Horlen C, Malone R, Bryant B, Dennis B, Carey T, Pignone M and Rothman R: Frequency of inappropriate metformin prescriptions. JAMA 287: 2504-2505, 2002.

17. Calabrese AT, Coley KC, DaPos SV, Swanson D and Rao RH: Evaluation of prescribing practices: Risk of lactic acidosis with metformin therapy. Arch Intern Med 162: 434-437, 2002.

18. Masoudi FA, Wang Y, Inzucchi SE, Setaro JF, Havranek EP, Foody JM and Krumholz HM: Metformin and thiazolidinedione use in Medicare patients with heart failure. JAMA 290: 81-85, 2003.

19. Stang M, Wysowski DK and Butler-Jones D: Incidence of lactic acidosis in metformin users. Diabetes Care 22: 925-927, 1999.

20. Saydah SH, Loria CM, Eberhardt MS and Brancati FL: Abnormal glucose tolerance and the risk of cancer death in the United States. Am J Epidemiol 157: 1092-1100, 2003.

21. Michels KB, Solomon CG, Hu FB, Rosner BA, Hankinson SE, Colditz GA and Manson JE; Nurses' Health Study: Type 2 diabetes and subsequent incidence of breast cancer in the Nurses Health Study. Diabetes Care 26: 1752-1758, 2003.

22. Will JC, Galuska DA, Vinicor F and Calle EE: Colorectal cancer: Another complication of diabetes mellitus? Am J Epidemiol 147: 816-825, 1998.

23. Everhart J and Wright D: Diabetes mellitus as a risk factor for pancreatic cancer. A meta-analysis. JAMA 273: 1605-1609, 1995.

24. Gapstur SM, Gann PH, Colangelo LA, Barron-Simpson R, Kopp P, Dyer A and Liu K: Postload plasma glucose concentration and 27 -year prostate cancer mortality (United States). Cancer Causes Control 12: 763-772, 2001.

25. Moore MA, Park CB and Tsuda H: Implications of the hyperinsulinaemia-diabetes-cancer link for preventive efforts. Eur J Cancer Prev 7: 89-107, 1998.

26. Evans JM, Donnelly LA, Emslie-Smith AM, Alessi DR and Morris AD: Metformin and reduced risk of cancer in diabetic patients. BMJ 330: 1304-1305, 2005.

27. Bowker SL, Yasui Y, Veugelers P and Johnson JA: Glucose-lowering agents and cancer mortality rates in type 2 diabetes: Assessing effects of time-varying exposure. Diabetologia 53: 1631-1637, 2010.

28. Libby G, Donnelly LA, Donnan PT, Alessi DR, Morris AD and Evans JM: New users of metformin are at low risk of incident cancer: A cohort study among people with type 2 diabetes. Diabetes Care 32: 1620-1625, 2009.

29. Shaw RJ, Lamia KA, Vasquez D, Koo SH, Bardeesy N, Depinho RA, Montminy M and Cantley LC: The kinase LKB1 mediates glucose homeostasis in liver and therapeutic effects of metformin. Science 310: 1642-1646, 2005.

30. Gwinn DM, Shackelford DB, Egan DF, Mihaylova MM, Mery A, Vasquez DS, Turk BE and Shaw RJ: AMPK phosphorylation of raptor mediates a metabolic checkpoint. Mol Cell 30: 214-226, 2008.

31. Inoki $\mathrm{K}, \mathrm{Li} \mathrm{Y}, \mathrm{Zhu} \mathrm{T}$, Wu J and Guan KL: TSC2 is phosphorylated and inhibited by Akt and suppresses mTOR signalling. Nat Cell Biol 4: 648-657, 2002.

32. Cantrell LA, Zhou C, Mendivil A, Malloy KM, Gehrig PA and Bae-Jump VL: Metformin is a potent inhibitor of endometrial cancer cell proliferation - implications for a novel treatment strategy. Gynecol Oncol 116: 92-98, 2010.

33. Stephenne X, Foretz M, Taleux N, van der Zon GC, Sokal E, Hue L, Viollet B and Guigas B: Metformin activates AMP-activated protein kinase in primary human hepatocytes by decreasing cellular energy status. Diabetologia 54: 3101-3110, 2011.

34. Gunton JE, Delhanty PJ, Takahashi S and Baxter RC: Metformin rapidly increases insulin receptor activation in human liver and signals preferentially through insulin-receptor substrate-2. J Clin Endocrinol Metab 88: 1323-1332, 2003.

35. Ben Sahra I, Laurent K, Loubat A, Giorgetti-Peraldi S, Colosetti P, Auberger P, Tanti JF, Le Marchand-Brustel Y and Bost F: The antidiabetic drug metformin exerts an antitumoral effect in vitro and in vivo through a decrease of cyclin D1 level. Oncogene 27: 3576-3586, 2008.

36. Calle EE, Rodriguez C, Walker-Thurmond $\mathrm{K}$ and Thun MJ: Overweight, obesity, and mortality from cancer in a prospectively studied cohort of U.S. adults. N Engl J Med 348: 1625-1638, 2003. 
37. Navaratnarajah R, Pillay OC and Hardiman P: Polycystic ovary syndrome and endometrial cancer. Semin Reprod Med 26: 62-71, 2008.

38. Dronavalli S and Ehrmann DA: Pharmacologic therapy of polycystic ovary syndrome. Clin Obstet Gynecol 50: 244-254, 2007.

39. Dumesic DA and Lobo RA: Cancer risk and PCOS. Steroids 78 782-785, 2013.

40. Zhou C, Gehrig PA, Whang YE and Boggess JF: Rapamycin inhibits telomerase activity by decreasing the hTERT mRNA level in endometrial cancer cells. Mol Cancer Ther 2: 789-795, 2003.

41. Xie Y, Wang YL, Yu L, Hu Q, Ji L, Zhang Y and Liao QP Metformin promotes progesterone receptor expression via inhibition of mammalian target of rapamycin (mTOR) in endometrial cancer cells. J Steroid Biochem Mol Biol 126: 113-120, 2011.

42. Tsuji K, Kisu I, Banno K, Yanokura M, Ueki A, Masuda K, Kobayashi Y, Yamagami W, Nomura H, Susumu N and Aoki D. Metformin: A possible drug for treatment of endometrial cancer. Open J Obstet Gynecol 2: 1-6, 2012.

43. Ko EM, Walter P, Jackson A, Clark L, Franasiak J, Bolac C, Havrilesky LJ, Secord AA, Moore DT, Gehrig PA and Bae-Jump V: Metformin is associated with improved survival in endometrial cancer. Gynecol Oncol 132: 438-442, 2014

44. Wolf I, Sadetzki S, Catane R, Karasik A and Kaufman B: Diabetes mellitus and breast cancer. Lancet Oncol 6: 103-111, 2005.

45. Liu B, Fan Z, Edgerton SM, Deng XS, Alimova IN, Lind SE and Thor AD: Metformin induces unique biological and molecular responses in triple negative breast cancer cells. Cell Cycle 8: 2031-2040, 2009.

46. Alimova IN, Liu B, Fan Z, Edgerton SM, Dillon T, Lind SE and Thor AD: Metformin inhibits breast cancer cell growth, colony formation and induces cell cycle arrest in vitro. Cell Cycle 8 : 909-915, 2009.

47. Sachdev D, Singh R, Fujita-Yamaguchi Y and Yee D: Down-regulation of insulin receptor by antibodies against the type I insulin-like growth factor receptor: Implications for anti-insulin-like growth factor therapy in breast cancer. Cancer Res 66: 2391-2402, 2006.

48. Zakikhani M, Dowling R, Fantus IG, Sonenberg N and Pollak M: Metformin is an AMP kinase-dependent growth inhibitor for breast cancer cells. Cancer Res 66: 10269-10273, 2006.

49. Jiralerspong S, Palla SL, Giordano SH, Meric-Bernstam F Liedtke C, Barnett CM, Hsu L, Hung MC, Hortobagyi GN and Gonzalez-Angulo AM: Metformin and pathologic complete responses to neoadjuvant chemotherapy in diabetic patients with breast cancer. J Clin Oncol 27: 3297-3302, 2009.

50. Kim J, Lim W, Kim EK, Kim MK, Paik NS, Jeong SS, Yoon JH, Park $\mathrm{CH}$, Ahn SH, Kim LS, et al: Phase II randomized trial of neoadjuvant metformin plus letrozole versus placebo plus letrozole for estrogen receptor positive postmenopausal breast cancer (METEOR). BMC Cancer 14: 170, 2014.

51. Goodwin PJ, Stambolic V, Lemieux J, Chen BE, Parulekar WR, Gelmon KA, Hershman DL, Hobday TJ, Ligibel JA, Mayer IA, et al: Evaluation of metformin in early breast cancer: A modification of the traditional paradigm for clinical testing of anti-cancer agents. Breast Cancer Res Treat 126: 215-220, 2011.

52. Iliopoulos D, Hirsch HA and Struhl K: Metformin decreases the dose of chemotherapy for prolonging tumor remission in mouse xenografts involving multiple cancer cell types. Cancer Res 71: 3196-3201, 2011.

53. Ness RB, Grisso JA, Klapper J, Schlesselman JJ, Silberzweig S, Vergona R, Morgan M and Wheeler JE: Risk of ovarian cancer in relation to estrogen and progestin dose and use characteristics of oral contraceptives SHARE Study Group. Steroid Hormones and Reproductions. Am J Epidemiol 152: 233-241, 2000.

54. Gotlieb WH, Saumet J, Beauchamp MC, Gu J, Lau S, Pollak MN and Bruchim I: In vitro metformin anti-neoplastic activity in epithelial ovarian cancer. Gynecol Oncol 110: 246-250, 2008.
55. Bodmer M, Becker C, Meier C, Jick SS and Meier CR: Use of metformin and the risk of ovarian cancer: A case-control analysis. Gynecol Oncol 123: 200-204, 2011.

56. Home PD, Kahn SE, Jones NP, Noronha D, Beck-Nielsen H and Viberti G; ADOPT Study Group; RECORD Steering Committee: Experience of malignancies with oral glucose-lowering drugs in the randomised controlled ADOPT (A Diabetes Outcome Progression Trial) and RECORD (Rosiglitazone Evaluated for Cardiovascular Outcomes and Regulation of Glycaemia in Diabetes) clinical trials. Diabetologia 53: 1838-1845, 2010.

57. Zhang ZJ and Li S: The prognostic value of metformin for cancer patients with concurrent diabetes: A systematic review and meta-analysis. Diabetes Obes Metab 16: 707-710, 2014.

58. Kumar S, Meuter A, Thapa P, Langstraat C, Giri S, Chien J, Rattan R, Cliby W and Shridhar V: Metformin intake is associated with better survival in ovarian cancer: A case-control study. Cancer 119: 555-562, 2013.

59. Pollak M: Metformin and other biguanides in oncology: Advancing the research agenda. Cancer Prev Res (Phila) 3: 1060-1065, 2010.

60. Fogarty S and Hardie DG: Development of protein kinase activators: AMPK as a target in metabolic disorders and cancer. Biochim Biophys Acta 1804: 581-591, 2010.

61. Xiao X, He Q, Lu C, Werle KD, Zhao RX, Chen J, Davis BC, Cui R, Liang J and Xu ZX: Metformin impairs the growth of liver kinase B1-intact cervical cancer cells. Gynecol Oncol 127: 249-255, 2012

62. Nevadunsky NS, Van Arsdale A, Strickler HD, Moadel A, Kaur G, Frimer M, Conroy E, Goldberg GL and Einstein MH: Metformin use and endometrial cancer survival. Gynecol Oncol 132: 236-240, 2014.

63. He X, Esteva FJ, Ensor J, Hortobagyi GN, Lee MH and Yeung SC: Metformin and thiazolidinediones are associated with improved breast cancer-specific survival of diabetic women with HER2 ${ }^{+}$breast cancer. Ann Oncol 23: 1771-1780, 2012.

64. Hou G, Zhang S, Zhang X, Wang P, Hao X and Zhang J: Clinical pathological characteristics and prognostic analysis of 1,013 breast cancer patients with diabetes. Breast Cancer Res Treat 137: 807-816, 2013.

65. Peeters PJ, Bazelier MT, Vestergaard P, Leufkens HG, Schmidt MK, de Vries F and De Bruin ML: Use of metformin and survival of diabetic women with breast cancer. Curr Drug Saf 8: 357-363, 2013.

66. Xiao Y, Zhang S, Hou G, Zhang X, Hao X and Zhang J: Clinical pathological characteristics and prognostic analysis of diabetic women with luminal subtype breast cancer. Tumour Biol 35: 2035-2045, 2014

67. Lega IC, Austin PC, Gruneir A, Goodwin PJ, Rochon PA and Lipscombe LL: Association between metformin therapy and mortality after breast cancer: A population-based study. Diabetes Care 36: 3018-3026, 2013.

68. Bayraktar S, Hernadez-Aya LF, Lei X, Meric-Bernstam F, Litton JK, Hsu L, Hortobagyi GN and Gonzalez-Angulo AM: Effect of metformin on survival outcomes in diabetic patients with triple receptor-negative breast cancer. Cancer 118: 1202-1211, 2012

69. Currie CJ, Poole CD, Jenkins-Jones S, Gale EA, Johnson JA and Morgan CL: Mortality after incident cancer in people with and without type 2 diabetes: Impact of metformin on survival. Diabetes Care 35: 299-304, 2012.

70. Romero IL, McCormick A, McEwen KA, Park S, Karrison T, Yamada SD, Pannain S and Lengyel E: Relationship of type II diabetes and metformin use to ovarian cancer progression, survival, and chemosensitivity. Obstet Gynecol 119: 61-67, 2012. 